\title{
DISTRIBUSI SEBARAN AKUIFER AIR TANAH MENGGUNAKAN DATA RESISTIVITAS METODE VERTICAL ELECTRICAL SOUNDING (VES) KONFIGURASI SCHLUMBERGER (STUDI KASUS KABUPATEN PALU PROVINSI SULAWESI TENGAH)
}

\author{
Yusuf Syifaurrohman, Widya Utama, dan Wien Lestari, Triswan Madani Ade Surya \\ Departemen Teknik Geofisika, Fakultas Teknik Sipil Lingkungan dan Kebumian, \\ Institut Teknologi Sepuluh Nopember (ITS) \\ e-mail: yusufsyifa95@gmail.com
}

\begin{abstract}
Abstrak. Daerah penelitian ini beririsan dengan peta Cekungan Air Tanah (CAT) Palu yang merupakan gabungan beberapa akuifer. Digunakan Vertical Electrical Sounding (VES) yang merupakan penggambaran sebaran nilai lapisan resistivitas secara vertikal 1 dimensi. Penelitian ini menggunakan konfigurasi schlumberger pada daerah penelitian dengan 12 titik ukur VES (VES1 - VES12). Hasil pengolahan VES dimodelkan 3 dimensi, selanjutnya dikorelasikan dengan peta CAT Palu untuk determinasi zona yang berpotensi sebagai akuifer. Geologi daerah penelitian terdiri dari Qap dan QTms yang masing-masing memiliki komponen pasir yang dapat berpotensi sebagai akuifer. Hasil pengukuran VES menunjukan sebaran nilai resistivitas sebesar 13 s.d. 1202 Ohm.m. Nilai resistivitas 20-120 Ohm.m merupakan zona interest yang diduga sebagai litologi batu pasir atau endapan pasir. Titik pengukuran yang terkorelasi dengan CAT Palu terdiri dari titik VES3, VES4, VES6, dan VES8 memiliki lapisan yang berpotensi lebih kuat sebagai akuifer dengan rentang kedalaman masing-masing 4,5-58,2 m; 8,7-36,3 m; 3,6-97,5 m; dan 33,299,2 $\mathrm{m}$. Penentuan daerah resapan air dilakukan dengan analisis topografi, dihasilkan area tersebut berada pada timur laut daerah penelitian dengan rentang elevasi 1400 s.d. 300 m. Pada daerah penelitian telah ditunjukkan potensi zona akuifer dengan tanda resistivitas yang cenderung lebih rendah dan litologi batu pasir atau endapan pasir yang memungkinkan adanya aliran fluida. Masalah ketersediaan air tanah diduga berkaitan dengan Masalah ketersediaan air tanah diduga berkaitan dengan kemampuan saturasi batuan.
\end{abstract}

Kata Kunci: : Akuifer, Air tanah, Kabupaten Palu, Resistivitas

\begin{abstract}
The research area is intercepted with the groundwater basin map of Palu which is a interconnected of several aquifers. Used Vertical Electrical Sounding (VES) which is a depiction of vertical resistivity layer in 1 dimension. This research used schlumberger configuration in the study area with 12 VES measuring points (VES1 - VES12). VES processing results are modeled in 3 dimensionally, then correlated with groundwater basin map of Palu for determination of potential zones as aquifers. The geology of the research area consists of Qap and QTms each of which have sandy contents that could potentially be aquifer. The result of VES measurement shows the distribution of resistivity value of 13-1202 Ohm.m. Resistivity value 20-120 Ohm.m is an alleged interest zone as the lithology of sandstone or sand deposits. . The measurement point correlated with the groundwater basin map of Palu consisting of VES3, VES4, VES6, and VES8 points has a potentially more potent layer as aquifer with a depth range of 4.5-58.2 $m ; 8,7-36,3 \mathrm{~m} ; 3,6-97,5 \mathrm{~m}$; and 33.2-99.2 m. Determination of the water catchment area was carried out by topographic analysis, resulting in the area located in the northeast of the study area with an elevation range of 1400 s.d. $300 \mathrm{~m}$. In the research area has been shown the potential of the aquifer zone with the sign of a resistivity that tends to be lower and the fitting lithology that allows the flow of fluid. The problem of groundwater availability is thought to be related to the ability of rock saturation.

Keywords: Aquifer, Groundwater, Palu District, Resistivity
\end{abstract}

\section{PENDAHULUAN}

Pada daerah penilitian terdapat permasalahan terkait ketersediaan air tanah. Padahal konsumsi air tanah oleh masyarakat sekitar merupakan kebutuhan utama dalam penggunaannya sehari hari
(Febriana, 2017). Perkiraan potensi akuifer air tanah dapat diketahui bila terdapat pendekatan model kapasitas akuifer air tanah.

Akuifer air tanah terbentuk dari proses geologi, merupakan batuan yang berfungsi untuk menyimpan 
air tanah. Salah satu litologi yang dapat memenuhi sifat fisis sebagai akuifer adalah batu pasir atau endapan batu pasir yang juga merupakan salah satu penyusun litologi daerah penilitian (Bisri, 2012). Secara regional Kabupaten Palu terdapat Cekungan Air Tanah (CAT) merupakan gabungan akuiferakuifer yang saling terhubung. Hal ini berkaitan erat dengan struktur geologi Palu yang merupakan Graben. Dapat ditentukan potensi air tanah pada suatu wilayah bila mengetahui penggambaran akuifer bedasarkan satuan (Zefftini, 2013). Dari penelitian sebelumnya diketahui akuifer utama pada CAT Palu merupakan akuifer tidak tertekan, sehingga tidak memungkinkan adanya lapisan impermeable diatas akuifer air tanah (Sosrodarsono dan Takeda, 2003; Zefftini, 2011).

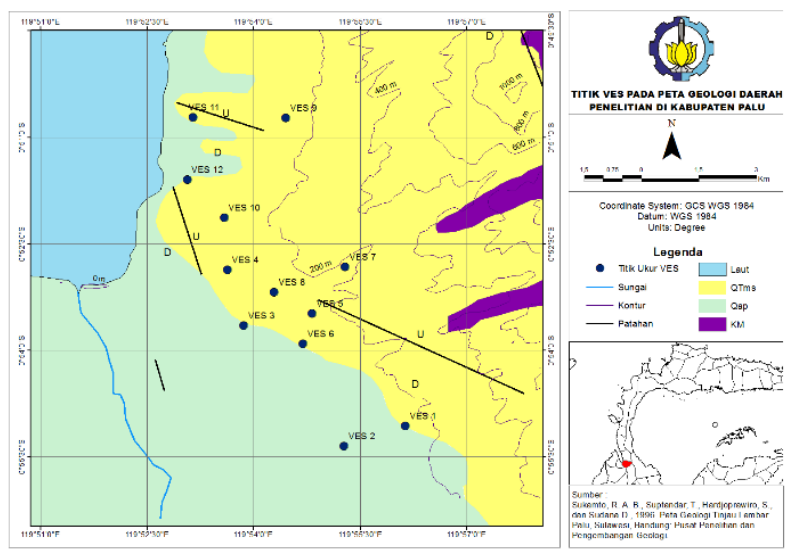

Gambar 1. Plotting titik pengukuran overlay dengan peta geologi

Geologi daerah penelitian meliputi formasi Qap yang merupakan endapan aluvium pantai yang terdiri dari kerikil, pasir, dan batu gamping. Sisi lain terdapat QTms yang terdiri dari batuan sedimen seperti konglomerat, batu pasir, batulumpur, batu gamping (Sukamto dkk., 1973). Hal terkait adalah permukaan pada daerah penelitian seluruhnya ditutupi oleh tanah jenis aluvium (SIMKOT, 2005). Kedua formasi menunjukan adanya zona pasiran atau batu pasir sehingga pada penelitian nantinya dapat ditentukan dugaan lapisan batu pasir atau endapan pasir yang dapat berperan sebagai akuifer dengan metode resistivitas (Ayi Syaeful Bahri dkk., 2017).

Vertical Electrical Sounding (VES) merupakan penggambaran resistivitas 1D secara vertikal. Sifat fisis air tanah yang umumnya lebih konduktif dapat memberikan kontras nilai resistivitas. Sehingga hal ini sesuai dengan prinsip metode geolistrik yang didasari pada perhitungan potensial bawah permukaan bumi (Telford, 1990). Sehingga VES merupakan metode yang efektif digunakan penilitian terkait air tanah (Massoud dkk., 2015).

Tujuan dari penilitian ini adalah Mengetahui sebaran nilai resistivitas lapisan batuan pada daerah pengukuran di Kabupaten Palu. Serta melakukan pemetaan zona potensi akuifer air tanah pada daerah pengukuran wilayah Kabupaten Palu dengan menggunakan metode VES konfigurasi schlumberger.

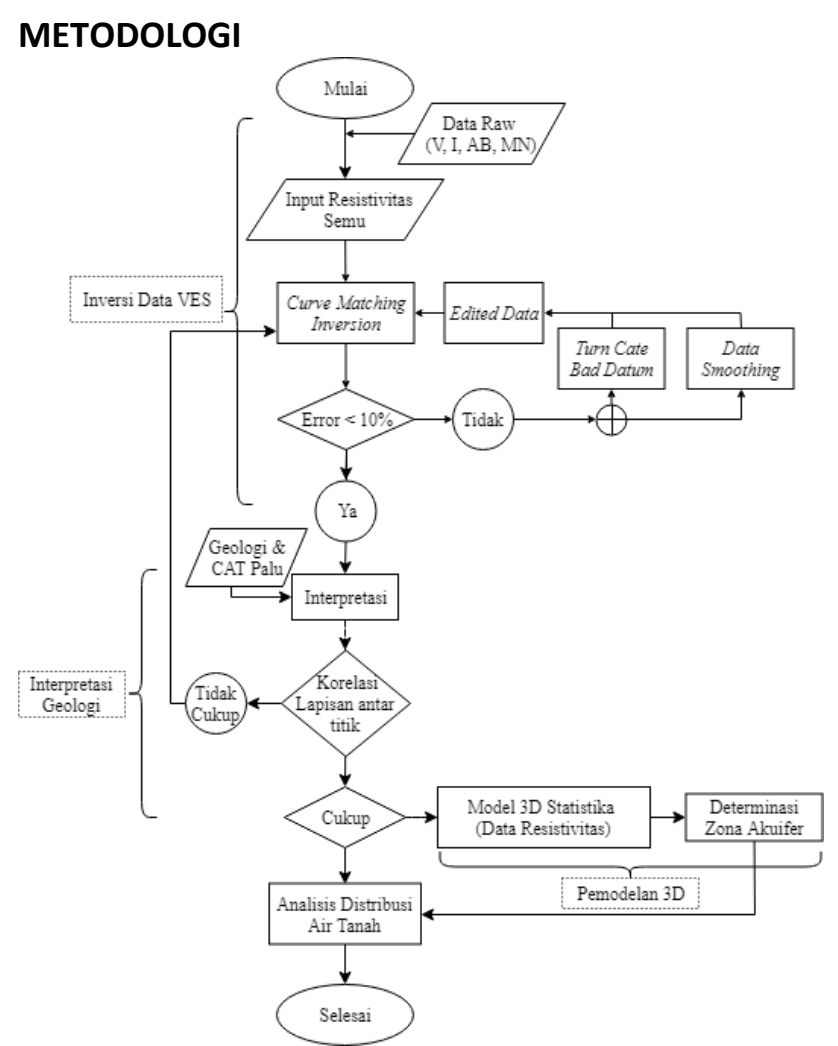

Gambar 2. Diagram alir penilitian

Penelitian ini menggunakan beberpa data. Data raw berupa data yang digunakan pada metode VES. Adapun data sekunder yang digunakan berupa peta geologi, peta hidrogeologi, peta kontur dan Shuttle Radar Topography Mission (SRTM).

Digunakan 12 titik ukur VES (VES1 - VES12) dengan panjang lintasan $200 \mathrm{~m}$ (VES3,VES4, VES11), $160 \mathrm{~m}$ (VES12), dan $400 \mathrm{~m}$ pada 8 titik VES lainnya. Hasil data raw yang didapatkan digunakan untuk menghitung resistivitas semu dengan persamaan sebagai berikut,

$$
\rho_{a}=K \frac{\nabla V}{I}
$$


$\rho_{a}$ adalah resistivitas semu, $\nabla V$ (beda potensial) dan $I$ (arus). Nilai resistivitas semu tergantung pada geometri dari susunan elektroda yang digunakan, yang didefinisikan dengan faktor geometri (K) dengan penjelasan persamaan berikut, (Reynold, 1997; Telford, 1990).

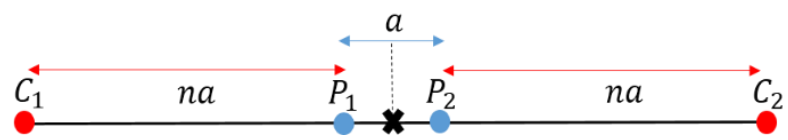

Gambar 3. Susunan elektroda konfigurasi schlumberger

$$
K=\pi n(n+1) a
$$

Gambar 3 merupakan ilustrasi dari konfigurasi schlumberger. Faktor " $n$ " yang akan mempengaruhi penetrasi kedalaman akan dikenakan pada jarak elektroda (a) $\mathrm{C}_{1}-\mathrm{P}_{1}, \mathrm{P}_{2}-\mathrm{C}_{2}$ (Loke, 2001).

Resistivitas semu hasil pengukuran tersebut digunakan sebagai data input saat proses inversi. Parameter yang dihasilkan melalui inversi adalah resistivitas asli dan ketebalan per lapisannya. Hasil inversi tersebut kemudian diinterpretasikan secara geologi untuk mendapatkan dugaan litologi per lapisannya. Determinasi zona yang berpotensi akuifer menggunakan data resistivitas yang menunjukan litologi batu pasir atau endapan pasir pada titik ukur VES yang berada diatas CAT. Memperjelas hal ini digambarkan pada gambar 4 dibawah ini,

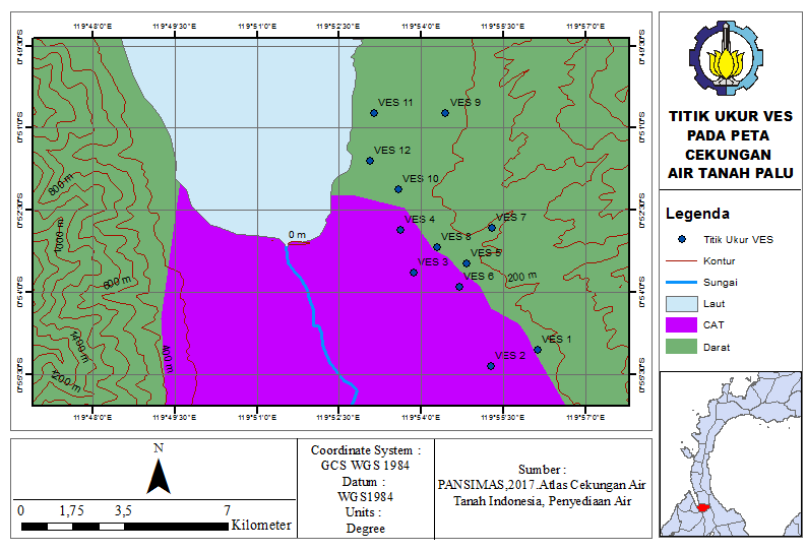

Gambar 4. Plotting titik pengukuran overlay dengan peta hidrogeologi

Menggambarkan hasil inversi VES digunakan interpolasi agar menghasilkan model 3 dimensi. Pada penelitian ini menggunakan persamaan statistika Inverse Distance Weighting (IDW). Secara umum IDW memberikan pembobotan pada interpolasi bedasarkan jarak titik sampel yang ada.

$$
Z_{p}=\frac{\sum_{i=1}^{n} \frac{Z_{i}}{\left(d_{i}\right)^{p}}}{\sum_{i-1}^{n} \frac{1}{\left(d_{i}\right)^{p}}} Z_{p} \quad \text { merupakan nilai parameter hasil }
$$
perhitungan IDW, sementara $Z_{i}$ adalah nilai parameter dari data. Notasi $d_{i}$ mewakili jarak antara titik data sample dengan titik yang akan dihitung nilai parameternya dengan IDW (Setianto dan Triandini, 2013). Faktor power $(p)$ merupakan satu-satunya parameter pengontrol selain dari data sample yang diberikan. Semakin besar nilai $p$ yang dieberikan maka nilai hasil perhitungan akan semakin mendekati nilai data sample dengan jarak terdekat (Pramono, 2008).

Analisis data membahas distribusi air tanah yang meliputi pembahasan dugaan penyebab adanya masalah ketersediaan air, arah distribusi pada zona dugaan akuifer, daerah recharge area menggunakan analisis topografi,

\section{Pengolahan Data Resistivitas Metode VES}

Pada tahap ini perhitungan resistivitas semu didasari dengan persamaan 1 dan 2. Posisi elektroda $\mathrm{C}_{1}-\mathrm{P}_{1}-\mathrm{P}_{2}-\mathrm{C}_{2}$ (A-M-N-B), arus listrik (Ampere), dan beda potensial (Volt) merupakan data raw yang digunakan. Resistivitas semu yang didapatkan kemudian digrafikkan dengan panjang $A B / 2$. Hasil dari grafik tersebut berpeluang terdapatnya datum outlier yang disebabkan oleh adanya noise. Hal tersebut dapat diatasi dengan melakukan Quality Control (QC) dengan memberikan nilai ubahan pada datum outlier agar nilai resistivitas semunya sesuai dengan tren kurva utama. Digunakan contoh pada gambar 5 sebagai berikut,

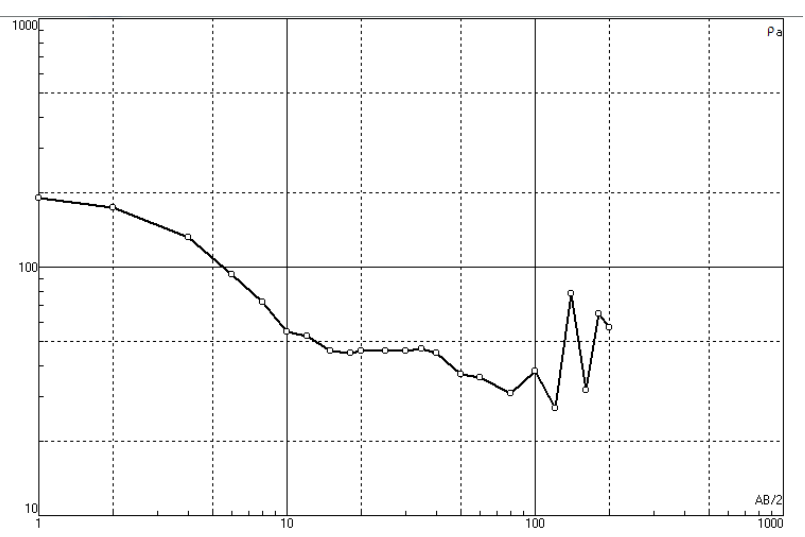

(a) 


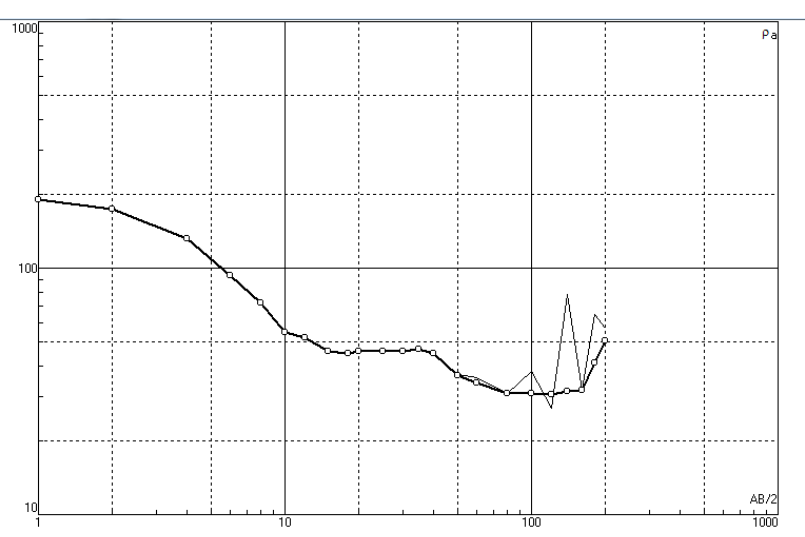

(b)

Gambar 5. (a) contoh tren resistivitas semu pengukuran sebelum $Q C$, (b) contoh tren resistivitas semu pengukuran setelah $Q C$

Tahap pengolahan $Q C$ tersebut didasari oleh percobaan tes parameter dengan forward model VES konfigurasi schlumberger untuk dua lapisan. Pada tes ini menggunakan lapisan resistivitas tinggi sebesar 150 Ohm.m dan lapisan resistivitas rendah $50 \mathrm{Ohm} . \mathrm{m}$. Hal ini dikarenakan pada penelitian didapati data resistivitas tinggi memiliki nilai sekitar diatas $100 \mathrm{Ohm} . \mathrm{m}$. Sehingga pada parameter tes dapat dilihat tren kurva resistivitas semu secara ideal.

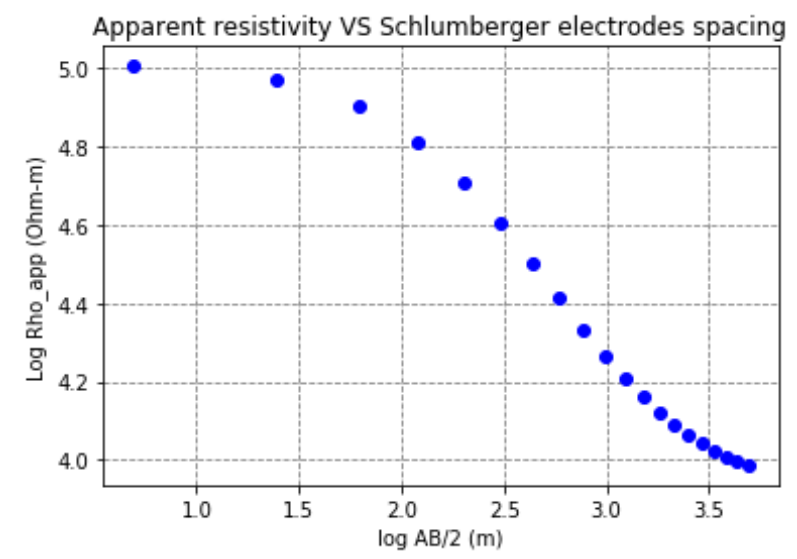

Gambar 6. Tes parameter forward model resistivitas tinggi ke lebih rendah (150 ke 50 Ohm.m)

Gambar 6 merupakan hasil tes lapisan 150 Ohm.m ke 50 Ohm.m. Pada percobaan digunakan ketebalan lapisan pertama $5 \mathrm{~m}$ dengan $A B / 2$ hingga $40 \mathrm{~m}$. Ditunjukkan pada hasil tren kurva resistivitas semu mempunyai nilai gradien yang negatif. Hal ini berarti nilai resistivitas semu semakin terpengaruh oleh lapisan resistivitas kedua yang memiliki nilai yang lebih rendah dibandingkan nilai resistivitas lapisan pertama dengan bertambahnya panjang jarak elektroda $A B$. Panjang jarak elektroda $A B$ mempengaruhi respon penetrasi listrik. Semakin panjang jarak tersebut maka respon resistivitas semu semakin terpengaruh oleh lapisan yang semakin dalam.

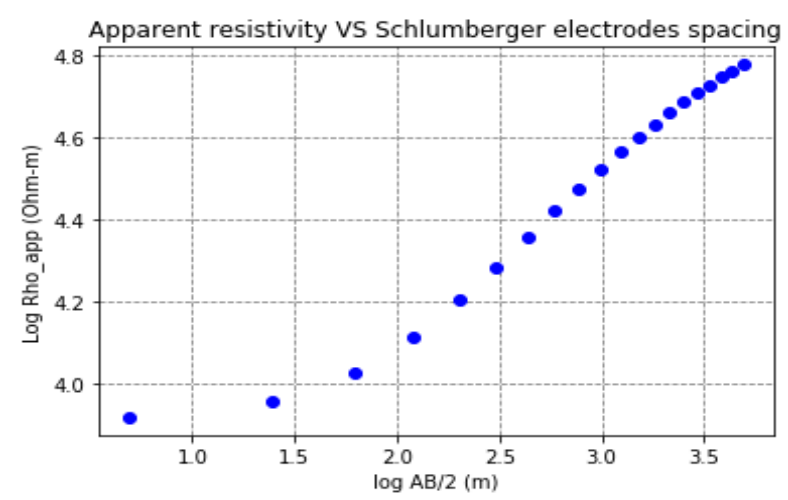

Gambar 7. Tes parameter forward model resistivitas rendah ke lebih tinggi (50 ke 150 Ohm.m)

Hasil respon resistivitas semu dari parameter tes kedua ditunjukkan pada gambar 7. Dimana lapisan pertama merupakan resistivitas rendah 50 Ohm.m sedangkan lapisan kedua memiliki resistivitas lebih tinggi (150 Ohm.m). Parameter tes ini menggunakan parameter ketebalan lapisan dan panjang lintasan yang sama dengan parameter tes pertama. Respon dari nilai resistivitas semu menunjukan hasil yang umumnya berkebalikan dari parameter tes pertama. Namun pada dasarnya respon ini dikarenakan oleh semakin mempengaruhinya lapisan kedua seiring dengan bertambahnya jarak elektroda AB.

Kedua paramater tes menunjukan hasil tren kurva resistivitas semu secara ideal. Data pengukuran yang didapati outlier dapat dilakukan $Q C$ dengan mengganti nilai datum outlier agar sesuai tren kurva yang ideal. Hal ini penting dilakukan karena tren kurva resistivitas semu merupakan pengontrol nilai eror hasil inversi yang menghasilkan parameter model resistivitas dan ketebalannya.

Hasil $Q C$ dari tiap titik ukur VES digunakan input data proses inversi 1D. Penilitian ini menggunakan metode curve matching inversion pada proses inversinya. Diatur jumlah lapisan resistivitas sesuai dengan jumlah tren resistivitas semu. Kemudian diatur nilai resistivitas asli dan ketebalannya sehingga grafik grafik resistivitas semu sintetik memiliki bentukan tren yang sama dengan grafik resistivitas semu pengukuran. 


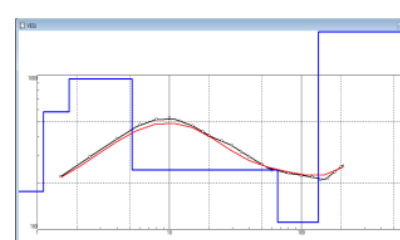

(a)

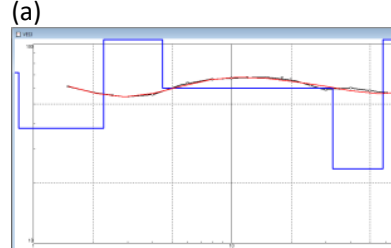

(c)

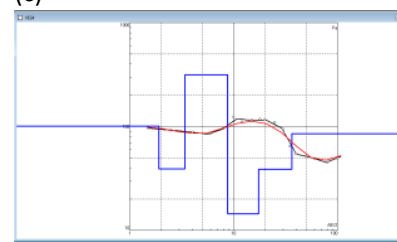

(e)

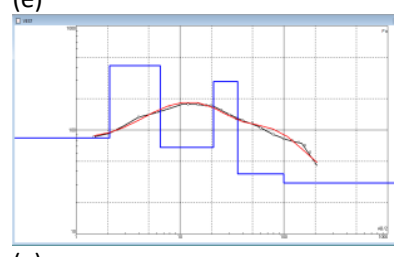

(g)

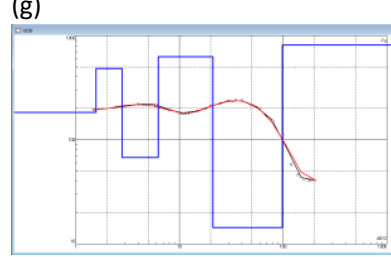

(i)

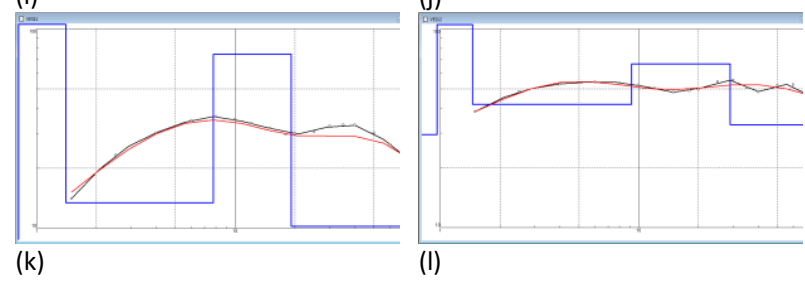

Gambar 8. Grafik hasil inversi VES (a) VES1, (b) VES2, (c) VES3, (d) VES4, (e) VES5, (f) VES6, (g) VES7, (h) VES8, (i) VES9, (j) VES10, (k) VES11, (I) VES12

Gambar 8 merupakan hasil dari inversi metode curve matching inversion. Penggambaran perlapisan hasil inversi disajikan dengan kurva step berwarna biru. Tiap pertemuan garis vertikal dan horisontal merupakan penggambaran satu lapisan. Garis vertikal merupakan gambaran nilai resitivitasnya dan horisontal merupakan gambaran ketebalan lapisannya. Pemberian nilai kedua parameter tersebut aan menghasilkan calculated rho apparent yang digambarkan tren kurva merah. Nilai eror yang merupakan selisih calculated rho apparent dan resitivitas semu pengukuran (kurva hitam), digunakan batasan maksimal sebesar $10 \%$.
Tabel 1. Hasil inversi VES

\begin{tabular}{|c|c|}
\hline VES1 & \\
\hline No. & Resistivitas $(\Omega \mathrm{m})$ \\
\hline 1 & 17 \\
\hline 2 & 57 \\
\hline 3 & 120 \\
\hline 4 & 24 \\
\hline 5 & 14 \\
\hline VES2 & \\
\hline No. & Resistivitas $(\Omega \mathrm{m})$ \\
\hline 1 & 8 \\
\hline 2 & 52 \\
\hline 3 & 14 \\
\hline 4 & 30 \\
\hline 5 & 77 \\
\hline VES3 & \\
\hline No. & Resistivitas $(\Omega \mathrm{m})$ \\
\hline 1 & \\
\hline 2 & \\
\hline 3 & 11 \\
\hline 4 & 6 \\
\hline 5 & \\
\hline VES4 & \\
\hline
\end{tabular}

No. Resistivitas $(\Omega \mathrm{m})$

1101

239

$3 \quad 314$

415

$5 \quad 39$

VES5

No. Resistivitas $(\Omega \mathrm{m})$

132

2320

368

4340

$5 \quad 34$

VES6

Eror : 6,11\%

Kedalaman (m)

1,1

2,1

5,2

35,7

126,0

Eror : 3,61\%

Kedalaman (m)

1,5

4,8

21,9

47,9

94,3

Eror : 2\%

Kedalaman (m)

0,8

2,3

4,5

32,4

58,2

Eror : 6,72\%

Kedalaman (m)

Eror : 5,77\%

Kedalaman (m)

$$
\begin{array}{r}
3,2 \\
5,6 \\
10,0 \\
31,6 \\
100,0
\end{array}
$$

No. Resistivitas $(\Omega \mathrm{m}) \quad$ Kedalaman $(\mathrm{m})$

1

122

2

2,0

3,6

5,4

3

457

$5 \quad 21$

VES7

30,9

97,5

Eror : $5,77 \%$

No. Resistivitas $(\Omega \mathrm{m})$

Kedalaman (m)

\begin{tabular}{rrr}
$\mathbf{1}$ & 84 & 2,1 \\
$\mathbf{2}$ & 415 & 6,5 \\
$\mathbf{3}$ & 68 & 21,1 \\
\hline
\end{tabular}




\begin{tabular}{|c|c|c|}
\hline 4 & 292 & 36,0 \\
\hline 5 & 38 & 100,0 \\
\hline VES8 & & Eror : $1,87 \%$ \\
\hline No. & Resistivitas $(\Omega m)$ & Kedalaman $(\mathrm{m})$ \\
\hline 1 & 103 & 0,9 \\
\hline 2 & 326 & 10,8 \\
\hline 3 & 118 & 26,2 \\
\hline 4 & 641 & 33,3 \\
\hline 5 & 78 & 99,2 \\
\hline VES9 & & Eror : 7,91\% \\
\hline No. & Resistivitas $(\Omega m)$ & Kedalaman (m) \\
\hline 1 & 182 & 1,6 \\
\hline 2 & 482 & 2,8 \\
\hline 3 & 68 & 6,2 \\
\hline 4 & 625 & 21,0 \\
\hline 5 & 14 & 98,3 \\
\hline VES1C & & Eror : $8,16 \%$ \\
\hline No. & Resistivitas ( $\Omega m)$ & Kedalaman (m) \\
\hline 1 & 62 & 0,4 \\
\hline 2 & 298 & 4,9 \\
\hline 3 & 40 & 36,6 \\
\hline 4 & 89 & 85,3 \\
\hline 5 & 269 & 105,2 \\
\hline VES11 & & Eror : 5,46\% \\
\hline No. & Resistivitas $(\Omega \mathrm{m})$ & Kedalaman (m) \\
\hline 1 & 7 & 0,7 \\
\hline 2 & 262 & 1,4 \\
\hline 3 & 13 & 7,8 \\
\hline 4 & 75 & 19,2 \\
\hline VES12 & & Eror : 3,46\% \\
\hline No. & Resistivitas $(\Omega m)$ & Kedalaman (m) \\
\hline 1 & 29 & 1,0 \\
\hline 2 & 213 & 1,5 \\
\hline 3 & 42 & 9,2 \\
\hline 4 & 67 & 28,9 \\
\hline
\end{tabular}

\section{INTERPRETASI DATA GEOLOGI DAN KORELASI DENGAN} CAT

Interpretasi geologi pada penilitian ini dilakukan pada VES2, VES3, VES4, VES6, dan VES8. Perlakuan tersebut dikarenakan pada titik tersebutlah yang berada diatas CAT Palu sesuai pada gambar 4 . VES2 dan VES3 adalah titik ukur berada pada formasi Qap yang didapati aluvium dan endapan pantai yang terdiri dari kerikil, pasir, dan batu gamping koral. Sedangkan VES4, VES6, dan VES8 berada pada formasi QTms yang didapati batu gamping, batu pasir, dan batu lumpur.
Tabel 2. Interpretasi litologi batuan dengan nilai range resistivitas

\begin{tabular}{rlr}
\hline No. & $\begin{array}{l}\text { Range } \\
\text { Resistivitas } \\
\text { (Ohm.m) }\end{array}$ & Dugaan Litologi \\
\hline $\mathbf{1}$ & $<20$ & Batu Lumpur \\
$\mathbf{2}$ & $20-120$ & Batu pasir \\
$\mathbf{3}$ & $>120$ & Batu Gamping \\
$\mathbf{4}$ & $0-800$ & Aluvium \\
\hline
\end{tabular}

Batu lumpur memiliki mineral clay yang sifat konduktifitasnya tinggi dan bersifat impermeable. Penelitian sebelumnya yang telah dilakukan mengenai CAT Palu menyatakan bahwa akuifer utama pada Palu merupakan akuifer tidak tertekan, sehingga lapisan impermeable tidak dapat muncul di lapisan bagian atas akuifer (Zefftini, 2011). Batu Pasir merupakan zona interest dari eksplorasi air tanah. Hal ini dikarenakan batu pasir memiliki kemampuan untuk menyimpan air tanah, karena bersifat berpori dan permeabel untuk air tanah. Alur penetuan zona akuifer tersebut sesuai dengan penilitian (Bahri dkk., 2017). Batu pasir merupakan batuan yang cenderung bersifat kompak. Oleh karena itu nilai resistivitas batu pasir diinterpretasi dalam range yang lebih besar dari pada range batu lumpur. Interpretasi ini juga didukung peneilitian terkait yang memiliki nilai resistivitas maksimal pada zona akuifer komponen pasir dengan nilai maksimal sekitar 100 Ohm.m (Gemilang dkk., 2018).

Tabel 3. Hasil interpretasi geologi VES2

\begin{tabular}{crrl}
\hline VES2 & & \multicolumn{2}{l}{ Eror : 3,61\% } \\
\hline No. & $\begin{array}{l}\text { Resistivitas } \\
(\Omega \mathrm{m})\end{array}$ & $\begin{array}{l}\text { Kedalam } \\
\text { an }(\mathrm{m})\end{array}$ & Litologi \\
$\mathbf{1}$ & 87 & 1,5 & Aluvium \\
$\mathbf{2}$ & 529 & 4,8 & Batu Gamping \\
$\mathbf{3}$ & 145 & 21,9 & Endapan Aluvium \\
$\mathbf{4}$ & 302 & 47,9 & Endapan Aluvium \\
$\mathbf{5}$ & 771 & 94,3 & Endapan Aluvium \\
\hline
\end{tabular}

VES2 merupakan titik ukur yang berasal dari formasi Qap. Pada lapisan tanah penutup permukaan merupakan aluivium pada seluruh titik ukur. Pada hasil inversi (gambar 8b) titik ini menunjukan 5 lapisan resistivitas. Selain pada lapisan top soil titik ini memiliki nilai resistivitas yang signifikan > 140 Ohm.m sehingga diinterpretasikan sebagai litologi endapan aluvium kompak.

Tabel 4. Hasil interpretasi geologi VES3 


\begin{tabular}{|c|c|c|c|}
\hline No. & $\begin{array}{l}\text { Resistivitas } \\
(\Omega \mathrm{m})\end{array}$ & $\begin{array}{l}\text { Kedalaman } \\
\text { (m) }\end{array}$ & Litologi \\
\hline 1 & 72 & 0,8 & Aluvium \\
\hline 2 & 38 & 2,3 & Aluvium \\
\hline 3 & 117 & 4,5 & Batu Gamping \\
\hline 4 & 60 & 32,4 & $\begin{array}{l}\text { Endapan Pasir } \\
\text { (ak) }\end{array}$ \\
\hline 5 & 24 & 58,2 & $\begin{array}{l}\text { Endapan Pasir } \\
\text { (ak) }\end{array}$ \\
\hline
\end{tabular}

Hasil inversi pada VES3 ditunjukan pada gambar 8c memiliki 5 lapisan bedasarkan nilai resitivitasnya. Titik VES3 berada pada formasi Qap. Lapisan pertama dan kedua merupakan lapisan penutup permukaan yakni aluvium. Hal ini dikarenakan korelasi dengan data lain yang mayoritas menunjukan batu gamping sebagai lapisan litologi batuan yang kedua dengan nilai kontras resistivitas yang tinggi. Kemudian lapisan ketiga menunjukan adanya anomali kontras nilai resitivitas yang lebih rendah diinterpretasikan sebagai komponen aluvium mayoritas endapan pasir yang terdapat fluida. Sehingga diberikan keterangan (ak) yang memiliki artian berpotensi sebagai akuifer.

Tabel 5. Hasil interpretasi geologi VES4

\begin{tabular}{rrrl}
\hline VES4 & & \multicolumn{2}{l}{ Eror : 6,72\% } \\
\hline No. & Resistivitas & Kedalam & Litologi \\
& $(\Omega \mathrm{m})$ & \multicolumn{1}{l}{ an $(\mathrm{m})$} & \\
$\mathbf{1}$ & 101 & 1,9 & Aluvium \\
$\mathbf{2}$ & 39 & 3,4 & Aluvium \\
$\mathbf{3}$ & 314 & 8,7 & Batu Gamping \\
$\mathbf{4}$ & 15 & 17,4 & Batu pasir (ak) \\
$\mathbf{5}$ & 39 & 36,3 & Batu pasir (ak) \\
\hline
\end{tabular}

Gambar 8d merupakan hasil inversi dari titik ukur VES4 yang menghasilkan 5 lapisan resistivitas. Hal serupa yang ditemui pada VES3 yang lebih mempertimbangkan lapisan litologi kedua merupakan batu gamping bila terdapat kontras resistivitas yang tinggi. Terlihat bahwa pada VES4 terdapat anomali rendah pada pada datum-datum bagian akhir yang berkaitan dengan bertambahnya kedalaman lapisan. Interpretasi geologi menghasilkan tiga lapisan litologi yang terdiri dari aluvium, batu gamping, dan batu pasir. Pada lapisan 4 diinterpretasikan sebagai batu pasir meskipun dengan nilai 15 Ohm.m yang lebih rendah dibandingkan dengan jangkauan nilai resitivitas batu pasir rata-rata pada penelitian ini. Hal ini dikarenakan akuifer utama pada palu merupakan akuifer tidak tertekan sehingga meskipun dengan nilai resistivitas batu lumpur $(<20 \mathrm{Ohm} . \mathrm{m})$ lapisan ini tetap diinterpretasikan sebagai batu pasir yang lebih memenuhi korelasi data kondisi geologi.

Tabel 6. Hasil interpretasi geologi VES6

\begin{tabular}{crrl}
\hline VES6 & & & Eror : 8,83\% \\
\hline No. & $\begin{array}{l}\text { Resistivitas } \\
(\Omega \mathrm{m})\end{array}$ & $\begin{array}{l}\text { Kedalam } \\
\text { an }(\mathrm{m})\end{array}$ & Litologi \\
& & 2,0 & Aluvium \\
$\mathbf{1}$ & 197 & 3,6 & Batu Gamping \\
$\mathbf{2}$ & 122 & 5,4 & Batu Pasir (ak) \\
$\mathbf{3}$ & 17 & 30,9 & Batu Pasir (ak) \\
$\mathbf{4}$ & 57 & 97,5 & Batu Pasir (ak) \\
$\mathbf{5}$ & 21 & & \\
\hline
\end{tabular}

Gambar $8 f$ merupakan hasil interpretasi pada titik ukur VES6 yang memiliki lima lapisan bedasarkan nilai resistivitasnya. Titik ukur VES6 terdapat tiga jenis lapisan bedasarkan interpretasi litologinya (aluvium, batu gamping, dan batu pasir). Pertimbangan interpretasi ini didasari oleh hubungan interpretasi pada titik VES yang lain. Pada titik ini terdapat lapisan batu pasir yang memiliki nilai $<20 \mathrm{Ohm} . \mathrm{m}$. Hal ini dilandasi alasan yang sama dengan pembahasan pada VES4. Pada titik ini mengahasilkan interpretasi data yang menunjukan adanya lapisan batu pasir yang diduga berperan sebagai akuifer dengan resistivitas rendah (17 Ohm.m, 59 Ohm.m, 21 Ohm.m).

Tabel 7. Hasil interpretasi geologi VES8

\begin{tabular}{lrrl}
\hline VES8 & \multicolumn{2}{c}{ Eror : 1,87\% } \\
\hline No. & $\begin{array}{l}\text { Resistivitas } \\
(\Omega \mathrm{m})\end{array}$ & $\begin{array}{l}\text { Kedalaman } \\
(\mathrm{m})\end{array}$ & Litologi \\
$\mathbf{1}$ & 103 & 0,9 & Aluvium \\
$\mathbf{2}$ & 326 & 10,8 & Batu Gamping \\
$\mathbf{3}$ & 118 & 26,2 & Selipan \\
& & & Sedimen \\
$\mathbf{4}$ & 641 & 33,3 & Batu Gamping \\
$\mathbf{5}$ & 78 & 99,2 & Batu Pasir (ak) \\
\hline
\end{tabular}

Gambar 8h merupakan hasil inversi dari titik ukur VES8 yang menghasilkan 5 lapisan bedasarkan nilai resistivitasnya. Hasil inversi dan interpretasi geologi titik VES8 ini mempunyai fenomena adanya nilai resistivitas rendah diantara nilai kontras resistivitas yang tinggi pada lapisan dua dan empat. Hal ini diinterpretasikan sebagai selipan sedimen yang diduga batu pasir, namun pada lapisan ini tidak 
diinterpretasikan sebagai lapisan yang berperan sebagai akuifer karena pada bawah lapisan ini merupakan batu gampig yang bersifat pori terbuka. Fenomena tersebut akan mengakibatkan fluida yang tertampung lebih mudah mengalir ke bawah. Oleh karena itu lapisan limalah yang diinterpretasi sebagai batu pasir yang diduga berperan sebagai akuifer. Pada VES8 didapati hasil interpretasi yang menunjukan adanya dugaan air tanah pada lapisan ke lima dengan kedalaman 33,3 m s.d. 99,2 m.

Hasil interpretasi menunjukan batu pasir yang berperan sebagai akuifer memiliki ketebalan yang cukup tinggi. Fenomena ini memungkinkan akan membawa air tanah mengalir lebih mudah ke bawah. Sehingga zona-zona resistivitas rendah yang berpotensi sebagai akuifer mayoritas berada pada lapisan bagian bawah.

Tabel 8. Potensi zona akuifer hasil korelasi titik ukur VES dengan peta CAT Palu

\begin{tabular}{lrrrr}
\hline Parameter & VES3 & VES4 & VES6 & VES8 \\
\hline $\begin{array}{l}\text { Elevasi } \\
\text { Permukaan (m) }\end{array}$ & 40,7 & 38,5 & 77,05 & 61,36 \\
$\begin{array}{l}\text { Kedalaman } \\
\text { Potensi Akuifer }\end{array}$ & $4,5-$ & $8,7-$ & $3,6-$ & 33,2 \\
(m) & 58,2 & 36,3 & 97,5 & - \\
& & & & 99,2
\end{tabular}

Hasil interpretasi yang ada kemudian dikorelasikan dengan peta CAT Palu. Hal ini dilakukan untuk memperkuat interpretasi VES. Korelasi ini akan mendeterminasi titik ukur yang berpotensi sebagai zona akuifer bedasarkan lokasi yang berada diatas CAT. Sehingga hasil interpretasi dipersempit dengan tujuan hasil penelitian ini dapat dijadikan referensi titik sumur air tanah yang lebih mudah. Tabel 8 menampilkan keterangan titik ukur VES yang berada diatas zona CAT Palu dan memiliki nilai resistivitas yang berpotensi sebagai zona akuifer.

\section{Pemodelan 3 Dimensi}

Penggambaran nilai resistivitas hasil inversi VES menggunakan metode geostatistika inverse distance weighting (IDW). Parameter power digunakan sebesar 2 pada interpolasi lateral dan vertikal. Pemilihan tersebut didasari oleh penelitian terkait (Pramono, 2008). Mempermudah visualisasi model 3 dimensi digunakan perbesaran 10 kali untuk keterangan panjang vertikalnya.

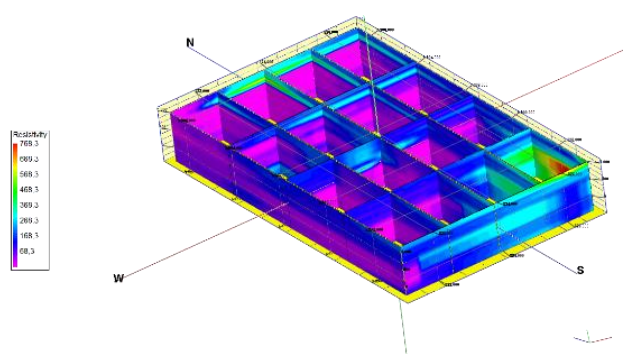

Gambar 9. Slicing model resistivitas 3 dimensi

Slicing (gambar 9) dilakukan agar nilai resistivitas dalam model dapat terlihat. Model tersebut menunjukkan dominasi nilai resistivitasdibawah 160 Ohm.m. Hal tersebut dikarenakan pada daerah pengukuran memiliki mayoritas litologi sedimen dan aluvium. Kontras resistivitas pada daerah antara timur dan selatan dikarenakan titik ukur daerah tersebut memiliki formasi yang berbeda.

Model kemudian di khususkan pada determinasi zona yang berpotensi akuifer saja dikarenakan rentang nilai resistivitas sulit dibedakan dan akuifer berada pada kedalaman tertentu. Model ini didasari dengan tabel 8 sebagai input.

Gambar 10 merupakan model hasil pengolahan resistivitas dengan rentang $20-120$ Ohm.m pada zona khusus yang berpotensi sebagai akuifer. Ditinjau dari estimasi dimensi model akuifer tersebut memiliki volume bidang sebesar 134.772.008 $\mathrm{m}^{3}$ dan luas bidang akuifer 2.235 .025 $\mathrm{m}^{2}$.

Daerah pengukuran yang meliputi CAT dan terdapat zona akuifer bedasarkan nilai resistivitas merupakan VES3, VES4, VES6, dan VES8. Dilihat dari elevasi model VES8 memiliki zona akuifer dengan capaian elevasi paling rendah. Distribusi air tanah akan mengarah ke area dengan elevasi yang lebih rendah sehingga VES8 diduga sebagai titik akumulasi distribusi air tanah. 


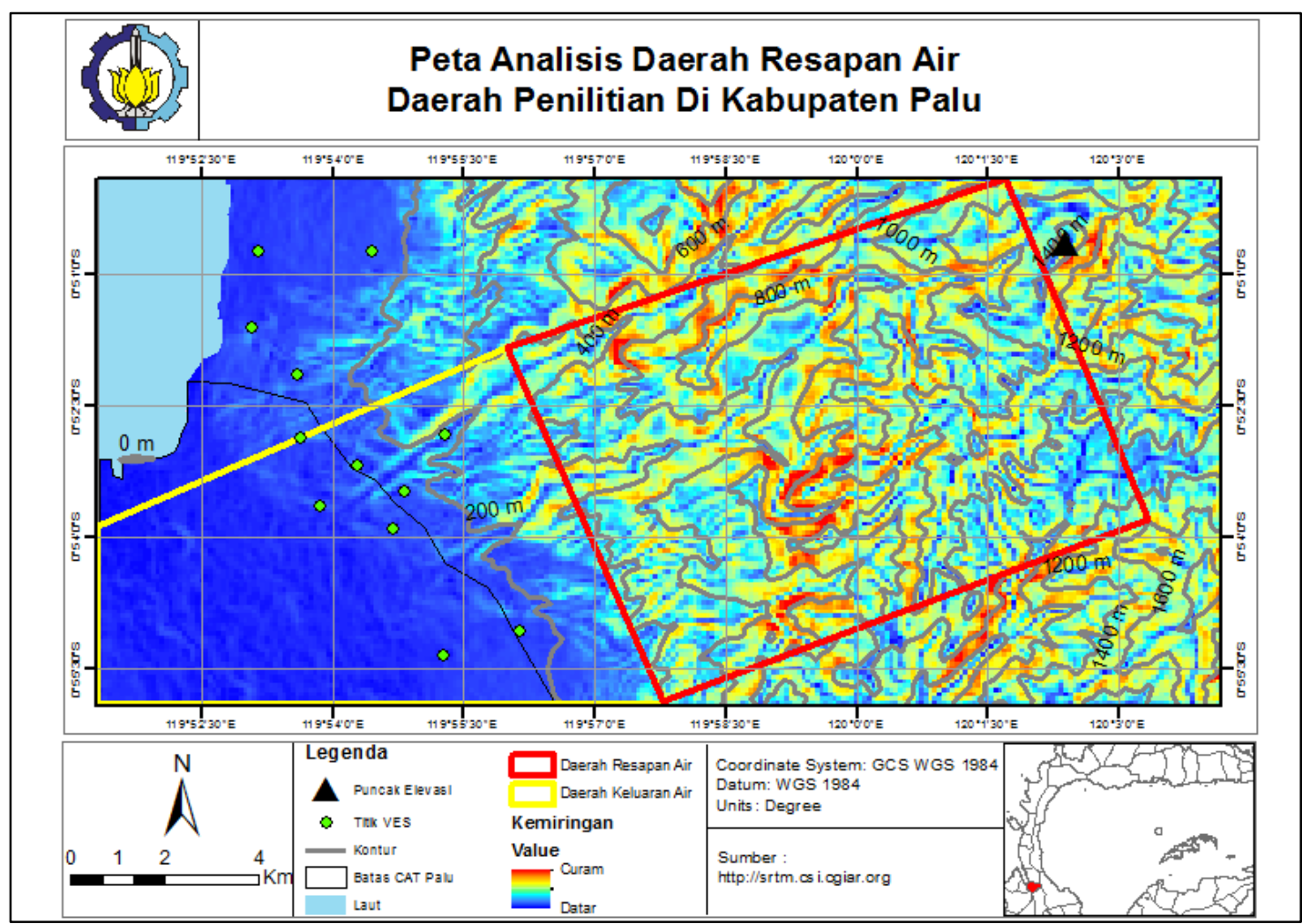

Gambar 10. Daerah resapan air tanah bedasarkan topografi

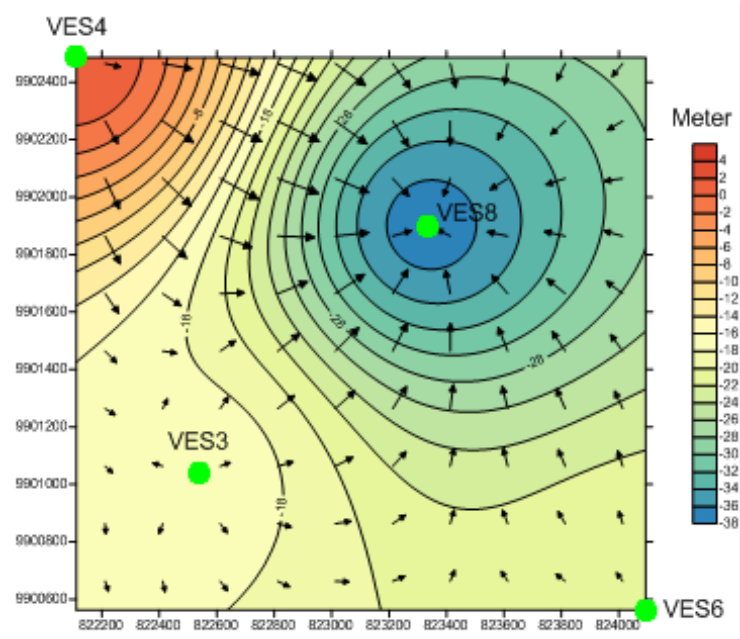

Gambar 11. Distribusi air tanah pada zona akuifer bedasarkan elevasi dan ketebalan terendah

Gambar 11 merupakan potensi zona akuifer dengan posisi model yang telah dikorelasi antara ketebalan lapisan zona akuifer dengan elevasinya. Pada model tersebut menghasilkan capaian elevasi terendah berturut dari yang terendah yakni VES8 ($37 \mathrm{~m}), \operatorname{VES} 6(-20 \mathrm{~m}), \operatorname{VES} 3(-17 \mathrm{~m})$, dan VES4 $(2 \mathrm{~m})$. Memperjelas distribusi air tanah bedasarkan elevasi, gambar 11 menyajikan peta kontur dengan arah distribusi air tanah. Pada gambar ini diambil elevasi terendah lapisan akuifer tiap titik untuk dipetakan.

\section{Analisis Daerah Resapan Air Tanah}

Metode yang digunakan untuk analisis daerah resapan air tanah pada penelitian ini menggunakan data variasi topografi. Hasil dari analisis pada tahap ini ditunjukkan dengan gambar 12 . Jalannya air dipengaruhi oleh variasi topografi dari elevasi tinggi pada daerah tersebut ditunjukkan dengan elevasi $1400 \mathrm{~m}$ ke elevasi rendah hingga $0 \mathrm{~m}$. Topografi yang curam dideterminasi sebagai daerah resapan air. Sedangkan pada daerah yang datar dideterminasi sebagai daerah keluaran air atau akumulasi air. Transisi antara daerah resapan dan keluaran ditandai dengan kontras kerapatan kontur dari yang rapat ke jarak interval kontur yang renggang. Secara kuantitatif pada penelitian ini daerah resapan air memiliki rentang ketinggian elevasi sekitar $1400 \mathrm{~m}$ s.d. $300 \mathrm{~m}$. Analisis pembahasan ini didasari oleh (Murtianto, 2014).

\section{PENUTUP}

\section{Simpulan dan Saran}

Hasil analisa penelitian yang telah dilakukan memiliki beberapa kesimpulan, antara lain: Sebaran 
nilai resistivitas lapisan batuan pada daerah pengukuran di Kabupaten Palu memiliki rentang dari 13-1202 Ohm.m. Bedasarkan hasil interpretasi litologi yang terdapat pada daerah pengukuran ini adalah aluvium, batu gamping, batu pasir, dan batu lumpur. Zona yang berpotensi sebagai akuifer bedasarkan nilai resistivitas (20-120 Ohm.m) dan korelasi dengan peta Cekungan Air Tanah (CAT) terdapat pada antara titik VES3, VES4, VES6, dan VES8. Akuifer air tanah merupakan akuifer pasiran dengan kemampuan saturasi rendah sehingga air tanah dengan mudah mengalir ke zona akuifer yang lebih rendah.

Bedasarkan hasil analisis data penulis menyarakankan pada penelitian selanjutnya menggunakan sumur pengamatan pada daerah yang berpotensi sebagai akuifer. Hal ini bertujuan untuk justifikasi data resistivitas dan mengetahui tingkat kesediaan air tanah bedasarkan beberapa parameter air pada zona akuifer. Adapun parameternya anatara lain adalah musim dan curah hujan. Dengan demikian dapat diketahui karakteristik distribusi air tanah.

\section{DAFTAR PUSTAKA}

Bahri, A.S., Widodo, A., Utama, W., Warnana, D.D., Aripin, P.R., Banuboro, A. dan Abdillah, R.A. (2017), "3D Resisitivity Data Modelling to Identify Aqcuifer Geometry - Field Study PDAM Groundwater Conservation Pandaan", Regional Conference in Civil Engineering (RCCE),

Bisri, M. (2012), Air Tanah; Studi Tentang Pendugaan Air Tanah, Sumur Air Tanah dan Upaya Dalam Konsevasi Air Tanah, Universitas Brawijaya Press, Malang.

Febriana, R.K.N. (2017), Identifikasi Sebaran Aliran Air Bawah Tanah (Groundwater) Dengan Metode Vertical Electrical Sounding (VES) Konfigurasi Schlumberger Di Wilayah Cepu, Blora, Jawa Tengah, FMIPA ITS.

Gemilang, W.A., Kusumah, G. dan Rahmawan, G.A. (2018), "Potensi Air Tanah Di Bagian Beach Ridge
Daerah Labuhan Bajau Dan Sekitarnya", Geosaintek, Vol.4, No.1, hal. 7-14.

Loke, M.H. (2001), Electrical imaging surveys for environmental and engineering studies.

Massoud, U., Soliman, M., Taha, A., Khozym, A. dan Salah, H. (2015), "1D and 3D inversion of VES data to outline a fresh water zone floating over saline water body at the northwestern coast of Egypt", NRIAG Journal of Astronomy and Geophysics, Vol.4, No.2, hal. 283-292.

Murtianto, H. (2014), Analisis dampak perubahan landuse pada recharge area lereng Gunung Merapi bagian selatan terhadap ketersediaan air tanah di dataran Yogyakarta, UPI.

Pramono, G.H. (2008), "Akurasi Metode IDW dan Kriging untuk Interpolasi Sebaran Sedimen Tersuspensi di Maros, Sulawesi Selatan", Forum Geografi, Vol.22, No.1, hal. 145-158.

Reynold, J. (1997), Introdution to Applied and Eviromental Geophysics, John Willey and Soon Ltd.

Setianto, A. dan Triandini, T. (2013), "Comparison of Kriging and Inverse Distance Weighted (IDW) interpolation methods in lineament extraction and analysis", Journal of Southeast Asian Applied Geology, Vol.5, No.1, hal. 21-29.

SIMKOT (2005), Peta Tanah Kota Palu Sistem Informasi Manajemen Perkotaan Kota Palu, Palu.

Sosrodarsono, S. dan Takeda, K. (2003), Hidrologi Untuk Perairan, PT. Pradnya Paramita, Jakarta.

Sukamto, R., Sumadirdja, H., Suptandar, T., Hardjoprawiro, S. dan Sudana, D. (1973), Peta Geologi Tinjau Lembar Palu Pusat Penelitian dan Pengembangan Geologi, Bandung.

Telford, W. (1990), Applied Geophysics, Cambridge University Press, New York.

Zefftini (2013), "Potensi Airtanah Di Cekungan Air tanah (CAT) Palu Berdasarkan Satuan Hidromorfologi dan Hidrogeologi", Jurnal Geografi, Vol.11, No.22, hal. 97-106.

Zefftini (2011), "Identifikasi batas lateral cekungan airtanah (cat) palu", SMARTek, Vol.9, No.4, hal. 337-349. 